\title{
Development and analytical validation of real-time PCR for the detection of Streptococcus agalactiae in pregnant women
}

Daniel F. Escobar ${ }^{1}$, Diego A. Diaz-Dinamarca ${ }^{1,2}$, Carlos F. Hernández ${ }^{1,3}$, Daniel A. Soto ${ }^{1}$, Ricardo A. Manzo ${ }^{1}$, Pedro I. Alarcón ${ }^{4}$, Camila H. Pinto ${ }^{1}$, Diego N. Bastias ${ }^{1,2,5}$, Carolayn N. Oberg-Bravo ${ }^{1,5}$, Robert Rojas ${ }^{6}$, Sebastián E. Illanes ${ }^{7,8}$, Alexis M. Kalergis ${ }^{2,9}$ and Abel E. Vasquez ${ }^{1,5,10,11^{*}}$ (D)

\begin{abstract}
Background: Group B Streptococcus (GBS) is the leading cause of invasive neonatal infection. In this study, we aimed to evaluate the analytical validation of qualitative real-time polymerase chain reaction (qPCR) as a means to detect GBS.

Methods: Genomic DNA (gDNA) was purified from 12 ATCC bacterial strains, two belonging to GBS and the remainder acting as negative controls. Additionally, gDNA was isolated from 21 strains of GBS from various serotypes (Ia, Ib and II-VIII). All gDNA was used to evaluate the analytical validation of the qPCR method employing a specific Taqman probe. Inclusivity, exclusivity, anticipated reportable range, the limit of detection and robustness were evaluated. The methods used are described in international guidelines and other existing reports. The performance of this qPCR method for detecting GBS was compared to other microbiological methods used with vaginal-rectal samples from pregnant women.

Results: Our qPCR method for detecting GBS was analytically validated. It has a limit of detection of $0.7 \mathrm{GE} / \mu \mathrm{L}$ and $100 \%$ analytical specificity. It detects all strains of GBS with the same level of performance as microbiological methods.

Conclusion: Data suggest that this qPCR method performs adequately as a means to detect GBS in vaginal-rectal swabs from pregnant women.
\end{abstract}

Keywords: Group B Streptococcus, qPCR, Surface immunogenic protein, Analytical validation, Bacterial detection

\footnotetext{
* Correspondence: avasquez@ispch.cl

'Sección de Biotecnología, Instituto de Salud Pública de Chile, Santiago,

Chile

${ }^{5}$ Escuela de Biotecnología y Escuela de Tecnología Médica, Facultad de

Ciencias, Universidad Santo Tomas, Santiago, Chile

Full list of author information is available at the end of the article
}

(c) The Author(s). 2020 Open Access This article is licensed under a Creative Commons Attribution 4.0 International License, which permits use, sharing, adaptation, distribution and reproduction in any medium or format, as long as you give appropriate credit to the original author(s) and the source, provide a link to the Creative Commons licence, and indicate if changes were made. The images or other third party material in this article are included in the article's Creative Commons licence, unless indicated otherwise in a credit line to the material. If material is not included in the article's Creative Commons licence and your intended use is not permitted by statutory regulation or exceeds the permitted use, you will need to obtain permission directly from the copyright holder. To view a copy of this licence, visit http://creativecommons.org/licenses/by/4.0/. The Creative Commons Public Domain Dedication waiver (http://creativecommons.org/publicdomain/zero/1.0/) applies to the data made available in this article, unless otherwise stated in a credit line to the data. 


\section{Background}

Streptococcus agalactiae, also known as Group B Streptococcus (GBS), is a leading cause of sepsis and meningitis in newborns and young infants [1-3]. Colonisation in pregnant women is estimated to be 11 to $35 \%$, and socioeconomic factors directly impact the percentage of carriers in the population [4]. Even though screening programs and intrapartum antibiotic prophylaxis has reduced early neonatal onset of disease, this bacterium remains the leading cause of infection in newborns in developing countries [2, 5, 6].

The Centers for Disease Control and Prevention (CDC) recommends that vaginal and rectal swabs be used to inoculate a selective enrichment medium such as Lim broth and subsequently subculture the product on blood agar plates [2]. For better sensitivity or test efficiency, an alternative such as Granada medium could be used. In this case, a color change indicates GBS growth [7]. Unfortunately, this approach has variable sensitivity [8-10] and is associated with long turnaround times $(18-72 \mathrm{~h})$. A more rapid test that retains high sensitivity and specificity compared to conventional culture-based methods is real-time polymerase chain reaction (qPCR) [11]. This method will not fail to detect non-hemolytic GBS, as do culture-based methods. Nonhemolytic and non-pigmented GBS are reportedly found in 1 to $4 \%$ of pregnant women [12].

It is crucial that sensitive and accurate qPCR strategies be developed so that the efficacy of intrapartum antibiotic prophylaxis can be determined [7]. Also essential is the analytical validation of the method by evaluating parameters such as analytical specificity (inclusivity and exclusivity), analytical sensibility (anticipated reportable range and limit of detection), linearity, efficiency and robustness, when used for detection. Quantitative methodologies require estimates of precision, accuracy and limits of quantification [13]. A validated analytical method confirms that GBS detection will be an accurate, precise and reliable measure of potency.

A surface immunogenic protein (SIP) is reportedly exposed at the surface of intact GBS cells no matter the serotype $[14,15]$. Because the sip gene is conserved in GBS, qPCR strategies have been used to successfully detect GBS in clinical studies [16-20]. However, an analytically validated qPCR assay for GBS using the target sip gene has not yet been reported.

We developed a qPCR method that uses the sip gene as its target (Intellectual Property PCT/IB2017/056506), and herein, we report the analytical validation and standardisation of that method using Clinical and Laboratory Standards Institute (CLSI) guidelines MM17-A (Validation and Verification of Multiplex Nucleic Acid Assays) and EP17-A (Protocols for Determination of Limits of Detection and Limits of Quantitation and Evaluation) [21-23].
Based on the work of others, the relevant parameters were identified as: selectivity (inclusivity and exclusivity), anticipated reportable range, the limit of detection (LOD), linearity, efficiency and robustness [24-28].

\section{Methods}

\section{Design of oligonucleotides}

Oligonucleotides were designed using free online software (Amplifx 1.7.0). They were based on the GBS sip gene, which codes for the GBS SIP (GenBank accession no.KX363665.1). After in silico analysis using Blast, the set of oligonucleotides showing the greatest sensitivity and specificity were: forward (SIP-F), GTTCCAGCAGCTAAAGAGGAAG; reverse (SIPR), CCGGTGCTACTTTAGCTACTGG; and probe (SIP-P), FAM-CACCAGCTTCTGTTGCCGCTGAAACACCAGCBHQ1 (Supplementary Fig. 1). A PCR product of 118 bp was obtained (Supplementary Fig. 2) (Intellectual Property PCT/ IB2017/056506).

\section{Collection of clinical samples}

Vaginal-rectal swabs were collected from pregnant women at a private health center and sent to the Health Public Institute of Chile ISPCH for GBS detection. All samples ( $n=103$ ) were collected between the 35 th and 37 th weeks of pregnancy. The study protocol was approved by the Ethics Committee of Clínica Dávila, and written informed consent was obtained from all study participants, agreeing that this work can be published. Samples were collected and submitted to Stuart transport medium at room temperature at the health center. After 2 hours, samples were cooled to $4{ }^{\circ} \mathrm{C}$ with ice packs, collected in a tertiary container and sent for analysis.

\section{Collection strains}

To perform standardisation and to determine the analytical parameters of the methodology, specific reference strains were obtained from the American Type Culture Collection (ATCC): Streptococcus agalactiae ATCC 12403, Streptococcus agalactiae ATCC 13813, Streptococcus pyogenes ATCC 21547, Staphylococcus aureus ATCC 25923, Enterococcus faecalis ATCC 29212, Streptococcus pneumoniae ATCC 49619, Escherichia coli ATCC 25922, Klebsiella pneumoniae ATCC 700603 and Klebsiella aerogenes ATCC 13048. Three non-ATCC strains, confirmed by the ISPCH, were included: Staphylococcus saprophyticus, Proteus spp. and Serratia marcescens. Isolates of axenic cultures of nine serotypes of GBS $(n=21)$ from patients with invasive infections (received from 2013 to 2018 by the Bacteriology Reference Laboratory of the ISPCH for confirmation) were also used. 


\section{Pretreatment of vaginal-rectal swabs}

All vaginal swabs were inoculated in $3 \mathrm{~mL}$ selective Todd-Hewitt broth and supplemented with nalidixic acid $(15 \mu \mathrm{g} / \mathrm{mL}$; Sigma-Aldrich, St. Louis, MO, USA) and gentamicin $(8 \mu \mathrm{g} / \mathrm{mL}$; Sigma-Aldrich), then were incubated for 18 to $24 \mathrm{~h}$ at $37^{\circ} \mathrm{C}$ in an atmosphere of $5 \%$ $\mathrm{CO}_{2}$. This procedure was duplicated; one was analysed using $\mathrm{qPCR}$ and the other using a microbiological method (Granada agar, Christie, Atkins and MunchPeterson [CAMP] test and latex agglutination; Fig. 1).

\section{DNA extraction from clinical samples}

Bacterial cultures were centrifuged at $10,000 \mathrm{~g}$ for 10 min. Then, from each pellet, a portion with a sterile tip was resuspended in $200 \mu \mathrm{L} 5 \%$ Chelex-100 (Sigma-Aldrich), $1 \mu \mathrm{L}$ commercial numan DNA $(10 \mathrm{ng} / \mu \mathrm{L})$ and $10 \mu \mathrm{L}$ lysozyme $(5 \mathrm{mg} / \mathrm{mL}$, Biological, Salem, MA, USA). The mixture was incubated at $37^{\circ} \mathrm{C}$ for $15 \mathrm{~min}$, then, $10 \mu \mathrm{L}$ proteinase $\mathrm{K}(2 \mathrm{mg} / \mathrm{mL}$, Merck) was added. Incubation at $56^{\circ} \mathrm{C}$ for $15 \mathrm{~min}$ was followed by a one-step inactivation $\left(95^{\circ} \mathrm{C}\right.$ for $\left.15 \mathrm{~min}\right)$. Finally, the lysate bacterial culture was centrifuged at $10,000 \mathrm{~g}$ for $3 \mathrm{~min}$ then stored at $-20{ }^{\circ} \mathrm{C}$ until qPCR analysis.

\section{DNA isolation from each strain}

All strains used for the determination of analytical parameters (previously characterised strains, both ATCC and non-ATCC) were cultured in blood agar, and gDNA was then extracted using E.Z.N.A. A manual bacterial
DNA kit (OMEGA Bio-Tek, Norcross, GA, USA) was applied following manufacturer instructions. Genetic material was eluted using $100 \mu \mathrm{L}$ eluent, then samples were screened for GBS using qPCR. The gDNA was quantified using a DS-11 spectrophotometer (Denovix, Wilmington, DE, USA). To determine the number of genomic equivalents, one GBS genome (2.16 Mbp) was obtained from the NCBI Reference Sequence (GenBank accession no. NC_004116.1), and its mass was calculated using: bp* $\mathrm{M}^{*} \mathrm{~N}_{\mathrm{A}}$, where bp is the size of the genome in bp, $\mathrm{M}$ is its molar mass in $\mathrm{g} / \mathrm{mol}$ and $\mathrm{N}_{\mathrm{A}}$ is Avogadro's number in $\mathrm{mol}^{-1}$. One genomic equivalent of GBS was found to have a mass of $2.4 \mathrm{fg}$.

\section{Real-time PCR procedure}

Assays were performed using $1 \mu \mathrm{L}$ gDNA template and a Stratagene Mx3000P thermocycler (Agilent Technologies, Santa Clara, CA, USA). To detect GBS, $1 \mu \mathrm{L}$ of each primer ( $4 \mu \mathrm{M}$ stock), $1 \mu \mathrm{L}$ probe ( $2 \mu \mathrm{M}$ stock) and $10 \mu \mathrm{L}$ Brilliant Multiplex Real-Time PCR Master Mix (Agilent Technologies, Santa Clara, CA, USA) were used. The optimal reaction conditions were found to be $95^{\circ} \mathrm{C}$ for $10 \mathrm{~min}$ followed by 40 cycles at $95^{\circ} \mathrm{C}$ for $15 \mathrm{~s}$, then $60^{\circ} \mathrm{C}$ for 1 min. A cycle threshold $(C t)$ value of 35 was used as the cut-off for positive fluorescence detection of the target.

\section{Analytical specificity}

Analytical specificity was evaluated in terms of selectivity, given the responsiveness of the method to selectively

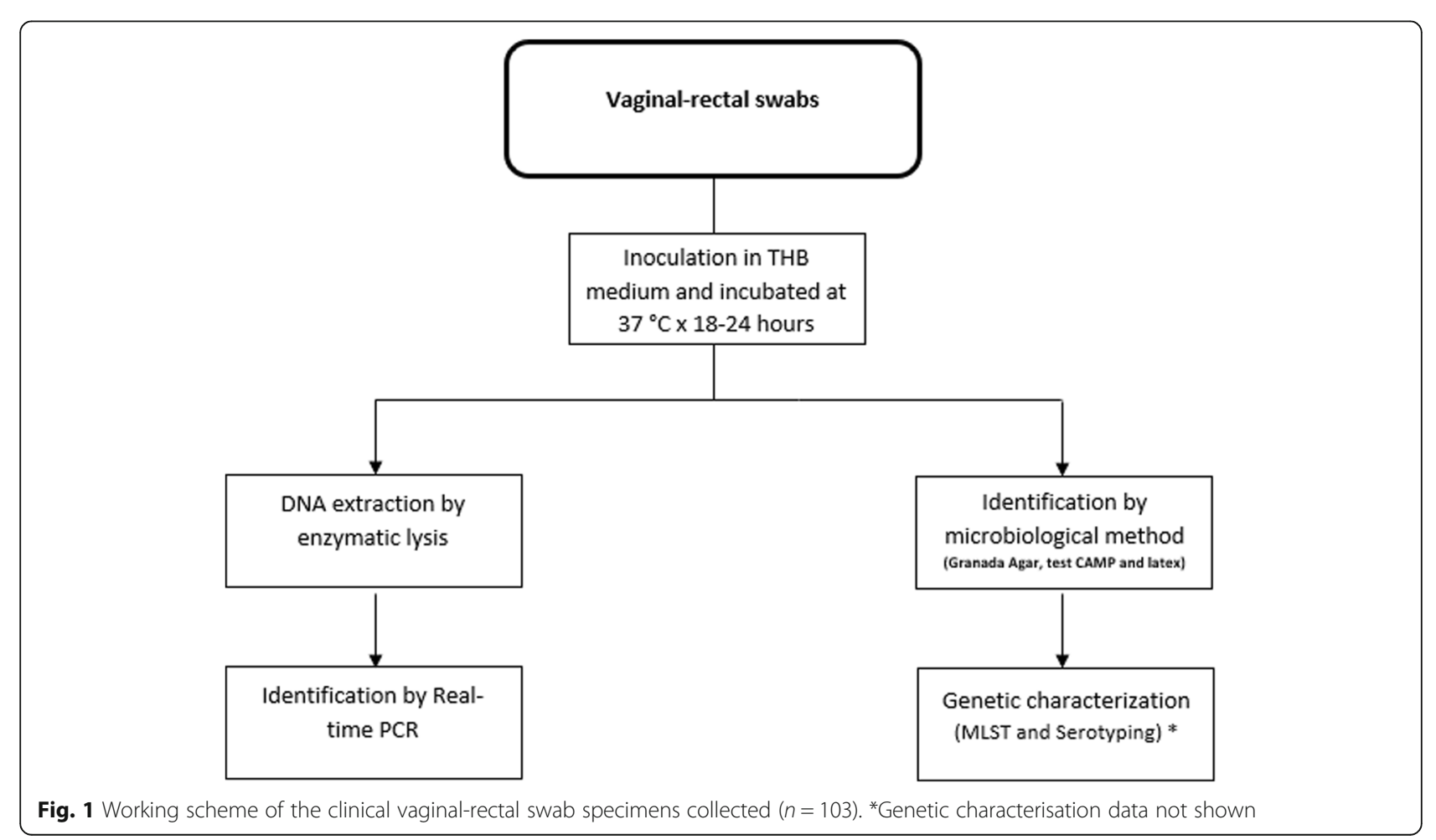


identify DNA sources using the sip target (GBS DNA) in non-GBS sources. This feature included:

\section{Inclusivity}

Purified gDNA from S. agalactiae ATCC 12403 was prepared at concentrations of 24,120 and $240 \mathrm{fg} / \mu \mathrm{L}(10,50$ and $100 \mathrm{GE} / \mu \mathrm{L}$ ) for nine available serotypes (Ia, Ib, II, III, IV, V, VI, VII and VIII). Each was run in duplicate.

\section{Exclusivity}

Purified DNA from $S$ pyogenes, S. aureus, E. faecalis, $S$. pneumoniae, E. coli, $K$. pneumoniae, $K$. aerogenes, $S$. saprophyticus, Proteus spp. and S. marcescens was prepared at concentrations of $1,10,100$ and $1000 \mathrm{pg} / \mu \mathrm{L}$ for each. Each was run in duplicate.

\section{Analytical sensitivity}

Analytical sensitivity, the lowest amount of analyte that can be detected with (a stated) probability was evaluated. However, exact values were not the focus. This feature includes:

\section{Anticipated reportable range}

Serial dilutions of gDNA from $S$. agalactiae ATCC 12403 resulted in final concentrations between 4.8E04 and $0.48 \mathrm{fg} / \mu \mathrm{L}$ (20,000 to $0.2 \mathrm{GE} / \mu \mathrm{L})$. Each dilution was amplified six-fold in four qPCR assays, providing 24 data points for the standard curve. Assigned (theoretical) versus measured values were converted to $\log _{10}(\mathrm{GE} / \mu \mathrm{L})$ and were then plotted for linear regression analysis.

\section{Limit of detection}

According to the CLSI guidelines, the LOD is the lowest DNA concentration that provides at least 95\% detectable results. Four concentrations of purified gDNA were adjusted to $9.6,19.2,38.4$ and $76.8 \mathrm{fg} / \mu \mathrm{L}$ (32 to $4 \mathrm{GE} / \mu \mathrm{L}$ ) and were analysed using qPCR. A blank (pooled negative samples) was also included. A total of 60 points and blanks were obtained over the course of five consecutive days. According to the CLSI protocol, to determine LOD, the limit of blank (LOB), the highest qPCR measures expected in samples devoid of analyte, must be determined.

\section{Robustness}

To evaluate a test's robustness, combinations between factors in standardised and alternative conditions were generated. The factors analysed were: master mix, concentration of primers, concentration of probe, upper alignment temperature, lower alignment temperature, equipment and operator. (Table 1).
Table 1 Robustness test as described by Broeders et al. (2014)

\begin{tabular}{lllllllll}
\hline Combination No & & & & & & & & \\
\hline Factor value & I & 2 & 3 & 4 & 5 & 6 & 7 & 8 \\
\hline A or a & A & A & A & A & a & a & A & a \\
B or b & B & B & b & b & B & B & B & b \\
C or c & C & C & C & C & C & C & C & C \\
D or d & D & D & d & d & d & d & D & D \\
E or $\mathbf{e}$ & E & e & E & e & e & E & E & E \\
F or f & F & f & f & F & F & f & f & F \\
G or g & G & g & g & G & g & G & G & g
\end{tabular}

(A) Standardised master mix; (a) alternative master mix; (B) standardised concentration of primers; (b) lower concentrations of primers; (C) standardised concentration of probe; (c) lower concentration of probe; (D) standardised alignment temperature; (d) upper alignment temperature; $(E)$ standardised alignment temperature; (e) lower alignment temperature; $(F)$ equipment used for validation; $(\mathrm{f})$ alternative equipment; $(\mathrm{G})$ operator $1 ; \mathrm{g})$ operator 2

\section{Precision}

Three concentrations of purified gDNA from $S$. agalactiae ATCC 12403 were adjusted to 4.8, 9.6 and $240 \mathrm{fg} / \mu \mathrm{l}$ (2, 4 and $100 \mathrm{GE} / \mu \mathrm{L}$ or $0.3,0.6$ and $\left.2 \log _{10} \mathrm{GE} / \mu \mathrm{L}\right)$. Precision was found using CLSI recommendations (the $20 \times 2 \times 2$ method, performing 2 daily runs of duplicates on 20 different days). The estimates of within-laboratory precision standard deviation $\left(S_{W L}\right)$ and repeatability standard deviation $\left(S_{R}\right)$ were calculated using: $S_{W L}=[\mathrm{V}$ day $\left.+\mathrm{V}_{\text {run }}+\mathrm{V}_{\text {error }}\right]^{1 / 2} ; S_{R}=\left[\mathrm{V}_{\text {error }}\right]^{1 / 2}$, respectively, where $\mathrm{V}_{\text {day }}, \mathrm{V}_{\text {run }}$ and $\mathrm{V}_{\text {error }}$ correspond to variance components of the day, run, and error, respectively. The variance component was calculated using MS, the mean of the square: $\quad V_{\text {error }}=M S_{\text {error }} ; \quad V_{\text {run }}=M S_{\text {run }}-M S_{\text {error } / n_{\text {rep }}}$ (number of replicates per run); $\mathrm{V}_{\text {day }}=\mathrm{MS}_{\text {day }}-\mathrm{MS}_{\text {run }} /$ $\mathrm{n}_{\text {run }} \mathrm{n}_{\text {rep }}$ (number of runs per day; number of replicates per run). The sum of the squares, provided by the twoway nested analysis of variance, was used to calculate MS, and DF, the degrees of freedom (for each source of variation $)$, was obtained as: $\mathrm{DF}_{\text {day }}=\mathrm{n}-1 ; \mathrm{DF}_{\text {run }}=\left(\mathrm{n}_{\mathrm{run}}\right.$ - 1) $n_{\text {day }} ; D F=N-n_{\text {daynrun; }}$; and $D F_{\text {total }}=N-1$, where $\mathrm{n}_{\text {day }}=20$ days; $\mathrm{n}_{\text {run }}=2$ runs per day, $\mathrm{n}_{\text {rep }}=2$ replicates per run and $N=80$ results per sample.

Two-sided 95\% confidence intervals (CIs) were calculated using the standard deviations of the degrees of freedom associated with repeatability $\left(d f_{R}\right)$ and the degrees of freedom associated with the laboratory $\left(d f_{W L}\right)$, where $\alpha_{\text {day }}=0.25, \alpha_{\text {run }}=0.25$ and $\alpha_{\text {error }}=0.5$, using the following formulas, respectively: $d f_{R}=\mathrm{N}-\mathrm{n}_{\text {daynrun }}$ and $d f_{W L}=\left(\alpha_{\text {day }} \mathrm{MS}_{\text {day }}+\alpha_{\text {run }} \mathrm{MS}_{\text {run }}+\alpha_{\text {error }} \mathrm{MS}_{\text {error }}\right)^{2} /\left(\alpha_{\text {day }}\right.$ $\left.\mathrm{MS}_{\text {day }}\right)^{2} / \mathrm{DF}_{\text {day }}+\left(\alpha_{\text {run }} \mathrm{MS}_{\text {run }}\right)^{2} / \mathrm{DF}_{\text {run }}+\left(\alpha_{\text {error }} \mathrm{MS}_{\text {error }}\right)^{2}$ / $\mathrm{DF}_{\text {error }}$. The CIs of repeatability were then computed using: $S_{R}\left[d f_{R} / \chi^{21-\alpha / 2}\right]^{2}$ and $S_{R}\left[d f_{R} / \mathrm{\chi} 2 \alpha / 2\right]^{2}$. The CIs of within-laboratory precision were computed using: $S_{W L}$ $\left[d f_{W L} / \chi^{21-\alpha / 2}\right]^{2}$ and $S_{W L}\left[d f_{W L} / \chi^{2 \alpha / 2}\right]^{2}$. Values obtained were re-expressed as \%CV using the data (Supplementary Fig. 3). 
a)

\section{GBS Serotype III (ATCC 12403)}

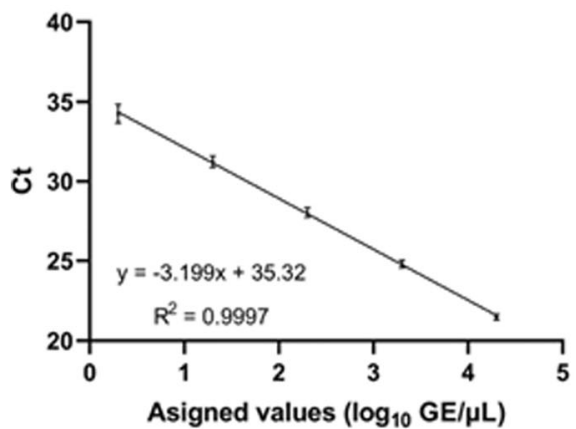

b)

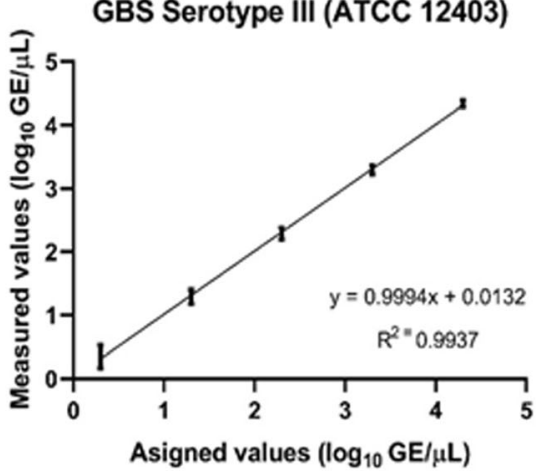

Fig. 2 Determination of the anticipated reportable range. a Standard curve between the value assignment $\left(\log _{10} \mathrm{GE} / \mu \mathrm{L}\right)$ and cycle threshold, as obtained from the points used to calculate real-time polymerase chain reaction efficiency $(\varepsilon)$. $\mathbf{b}$ Linear regression of the points on the standard curve between the assigned values and those obtained from measurements $\left(\log _{10} \mathrm{GE} / \mu \mathrm{L}\right)$. Also shown is the equation obtained from the model

\section{Quality assurance of the results}

Parallel to the clinical samples, commercial exogenous internal controls were run to rule out errors in the DNA purification process: A TaqManRNase P Detection Reagent Kit (Applied Biosystems, CA, USA) was applied following manufacturer instructions. The thermal profile conditions were the same as those used for amplification of the sip gene.

\section{Statistical analysis}

The GraphPad Prism 6 software (GraphPad Software, La Jolla, CA, USA) was used to carry out ANOVA analysis to determine the precision of the method and normal data distribution tests for choose the equation that determined the LOB and LOD, according to guidelines provided by CLSI documents EP05A3 and EP17-A, respectively.

\section{Results}

\section{Determining the analytical parameters of the qPCR assay} of GBS

Analytical validation of the qPCR assay was obtained using the parameters specified. The first to be determined was necessarily the anticipated reportable range. The high and low concentrations were measured in GEs per microliter. The anticipated reportable range, determined by constructing two standard curves, showed a linear correlation between the expected and obtained values $\left(R^{2}=0.9937\right)$ and between the assigned values for $C t$ and those found by the analytical software $\left(R^{2}=\right.$ 0.9997) when the analyte was between 20E04 and $2 \mathrm{GE} /$ $\mu \mathrm{L}$ (Fig. 2). The sixth point on the curve $(0.2 \mathrm{GE} / \mu \mathrm{L})$ was not amplified in any of the 24 replicates run during the four tests designed to determine this parameter. The $C t$ values at the lowest detectable dilution $(2 \mathrm{GE} / \mu \mathrm{L})$ ranged from 33.06 to 35.36 . The LOD $(0.7 \mathrm{GE} / \mu \mathrm{L})$ correlated with the results of the anticipated reportable
Table 2 Summary of results for each parameter evaluated in the analytical validation

\begin{tabular}{l}
\hline Validation parameters \\
\hline Inclusivity (detectable for $\mathbf{q P C R})(\mathbf{f g} / \boldsymbol{\mu L})$ \\
GBS serotype Ia $(n=3)$ \\
GBS serotype Ib $(n=2)$
\end{tabular}

Exclusivity (non-detectable qPCR) (0.1 to $1000 \mathrm{pg} / \mu \mathrm{L}$ )

S. pyogenes ATCC 12384

S. aureus ATCC 25923

E. faecalis ATCC $29212 \quad$ ND

S. pneumoniae ATCC 49619

E. coli ATCC 25922 ND

K. pneumoniae ATCC 700603 ND

K. aerogenes ATCC 13048 ND

S. saprophyticus ND

Proteus spp ND

S. marcescens ND

Reportable range $(\mathrm{GE} / \mu \mathrm{L})$

GBS ATCC 12403 serotype III 20.000-2

Limit of detection $(\mathrm{GE} / \mu \mathrm{L})$

GBS ATCC 12403 serotype III 0.7

Robustness

GBS ATCC 12403 serotype III (\% correct positives) 100

Samples non-GBS (\% correct negatives) 100

PCR efficiency $(\varepsilon)(\%) \quad 105.4$

Linearity $\left(R^{2}\right)$

0.9937

$\mathrm{fg} / \mu \mathrm{L}$ femtograms in 1 microliter, $p g / \mu L$ picograms in 1 microliter, $G E / \mu L$ genomic equivalents in 1 microliter, ND not detectable, $R^{2}$ correlation coefficient 


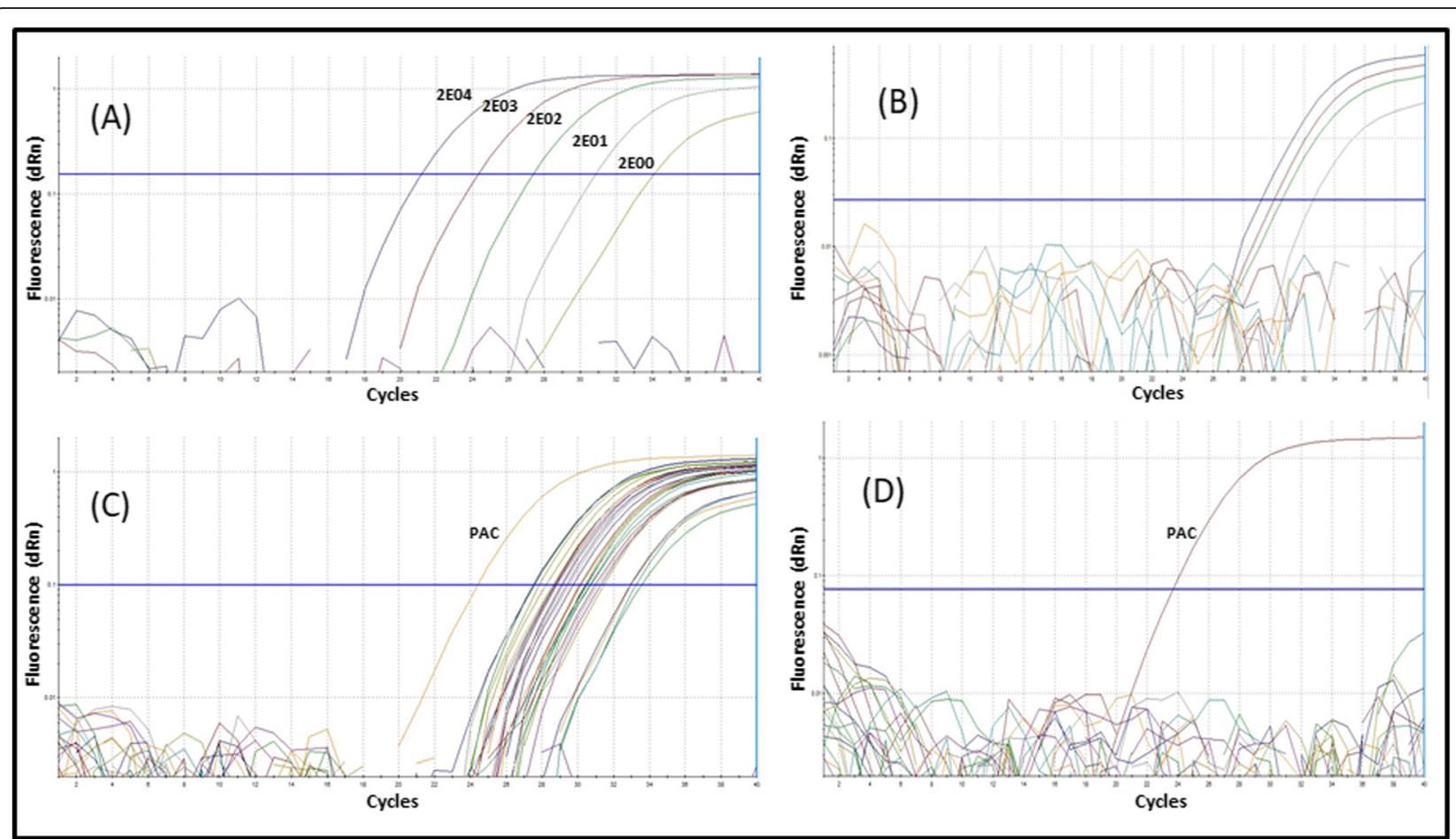

Fig. 3 Amplification curves of measured parameters. Positive, negative and no-template controls were included in all reactions. a Standard curve (2E04-2 GE/ $\mu \mathrm{L}$ ) constructed to determine the anticipated reportable range. b Amplification of curves (32-4 GE/ $\mu \mathrm{L})$ used to determinate the limit of detection. The pool of samples lacking GBS strains did not produce an amplification signal. c Curves showing the amplification signals from all GBS serotypes tested, used to determine the inclusivity parameter. $\mathbf{d}$ Curves for negatives, samples from non-GBS strains, used to determinate the exclusivity parameter. Note. PAC: positive amplification control for GBS

range, which lacked a detection signal when dilution was between 2 and $0.2 \mathrm{GE} / \mu \mathrm{L}$.

Exclusivity tests demonstrated that qPCR did not detect DNA in the range of 1 to $1000 \mathrm{pg} / \mu \mathrm{L}$ for $S$. pyogenes ATCC 21547, S. aureus ATCC 25923, E. faecalis ATCC 29212, S. pneumoniae ATCC 49619, E. coli ATCC 25922, K. pneumoniae ATCC 700603, K. aerogenes ATCC 13048, S. saprophyticus, Proteus spp. or S. marcescens. The 21 strains that corresponded to 9 of 10 available serotypes (Ia, Ib and II to VIII) and the $\gamma$ hemolytic strain S. agalactiae ATCC 13813 (serotype II) were detected at low DNA concentrations $(24 \mathrm{fg} / \mu \mathrm{L}$ or $10 \mathrm{GE} / \mu \mathrm{L}$ ), revealing that $\mathrm{qPCR}$ is inclusive and able to independently detect the various strains of the serotype. Each parameter was found to have an analytical specificity of $100 \%$ (Table 2; Fig. 3). Robustness was shown: Every combination produced an amplification signal, and $C t$ values remained between 32 and 34 .

\section{Comparative analysis between the microbiological method and qPCR for detecting GBS in vaginal-rectal swabs from pregnant women}

In total, 103 vaginal-rectal swabs (clinical samples) were analysed to confirm the presence of GBS. Samples were analysed blindly, and the results of the qPCR assays were compared to those found using a microbiological method. With the latter (a Granada agar plate, CAMP test and latex agglutination), GBS was found in 15 samples. The same was true for qPCR (Table 3; Fig. 4).

\section{Discussion}

A qPCR method to directly identify GBS from vaginalrectal swabs after an enrichment process in ToddHewitt broth was successfully developed. This methodology provides results that are the same as those obtained using the microbiological method routinely used in clinical laboratories. The qPCR methodology is quick and easy to interpret by technical health personnel, and it can be incorporated into a working algorithm to identify GBS. Analytical validation was performed by extracting gDNA using proteinase $\mathrm{K}$, lysozymes and Chelex-

Table 3 Confirmatory analysis of 103 clinical samples obtained from pregnant women

\begin{tabular}{llll}
\hline Result & Tests & Microbiological Method & $\begin{array}{l}\text { Total of } \\
\text { samples } \\
\text { analyzed }\end{array}$ \\
\cline { 2 - 4 } & $\mathbf{q P C R}$ & 15 & 103 \\
\hline Positive & 15 & 88 & \\
Negative & 88 & 88 & \\
\hline
\end{tabular}




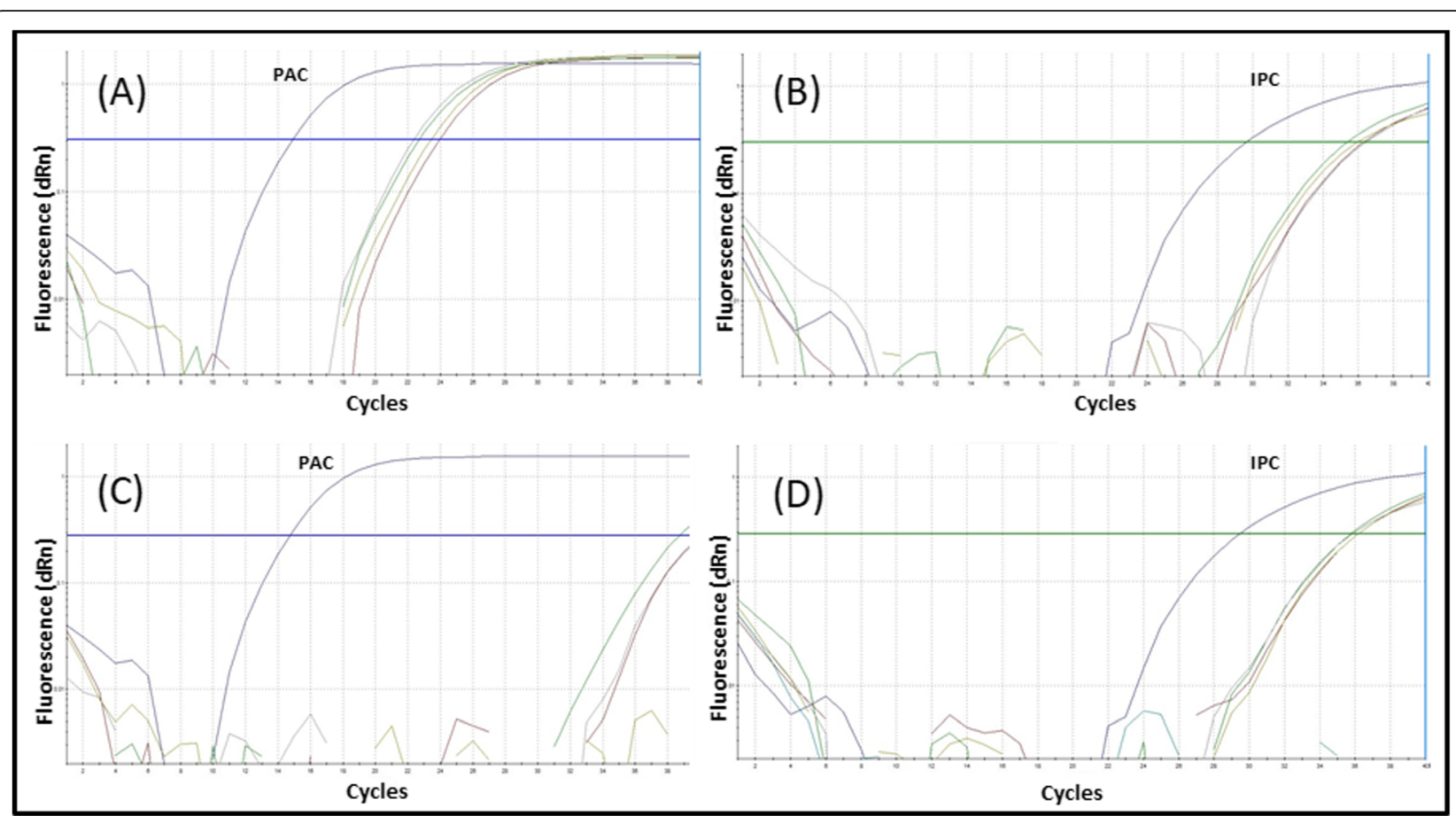

Fig. 4 Amplification plots with representative curves for positive and negative samples. Positive, negative and no-template controls were included in all reactions. a Amplification curves for the sip gene fragment from positive samples. $\mathbf{b}$ Amplification curves for internal positive controls from positive samples. c Amplification curves for the sip gene fragment from negative samples. $\mathbf{d}$ Amplification curves for internal positive controls from negative samples Note. IPC: internal positive control (exogenous, gene coding for the RNA subunit of ribonuclease P); PAC: positive amplification control for GBS

100 , reducing costs compared to a genomic DNA purification kit. This methodology is advantageous compared to others because it can detect low concentrations of genomic DNA $(2 \mathrm{GE} / \mu \mathrm{L})$ and can potentially be used as a GBS screening tool at delivery directly from a vaginal swab. A disadvantage is that the CDC does not recommend this practice. Moreover, molecular methods are limited in GBS detection because antibiotic resistance genes have not yet been incorporated into the PCR primer set. Doing so could enable the development of a rapid test that will provide additional information such as antibiotic susceptibility, for example, in the context of a penicillin allergy [29]. Meanwhile, microbiological analyses are recommended for determining susceptibility.

Several molecular diagnostic tools are emerging as potential candidates for more rapid identification of invasive GBS disease or to rapidly identify women colonised with GBS [29]. Rapid diagnostic tests for invasive diseases include the MinIon ${ }^{\circ}$, loop-mediated isothermal amplification [17] and optical immunoassays. Those for rapid intrapartum colonisation screening include PCRbased methods [30]. However, publicly available data for the analytical validation of these methods for GBS screening in a clinical setting are lacking. Our analytical validation method assessed the performance of qualitative qPCR strategies based on the TaqMan probe for
GBS detection, and it was conducted according to international guidelines. The sip gene from GBS was used as a molecular target, and inclusivity and exclusivity were estimated using gDNA from stocks of various bacterial strains. The analytical value of this methodology is in its anticipated reportable range $(20,000$ to $2 \mathrm{GE} / \mu \mathrm{L})$ and its LOD $(0.7 \mathrm{GE} / \mu \mathrm{L})$. Additionally, it has a high level of precision in repeatability conditions, reinforcing its applicability (Supplementary Fig. 3, Supplementary Table 1 and Supplementary Table 2). During pregnancy, rectovaginal colonisation of GBS is not persistent; it is characterised by a high rate of new acquisitions and a loss of colonisation over the course of pregnancy [31]. A culture-based method applied to samples taken between the 35th and 37th weeks of gestation might fail to detect all colonisations at delivery because GBS could infect between sampling and the onset of labor. For this reason, an intrapartum screening strategy using a qPCR method to identify and quantify GBS would help avoid riskfactor-based screening [32]. Compared to GBS cultures in enriched media, PCR has better sensitivity and specificity, ranging from $62.5-100 \%$ and $84.6-100 \%$, respectively [31].

To date, the gold standard for detecting GBS is the microbiological method, which is inexpensive and easy to perform. However, it fails to detect non-hemolytic 
GBS strains, and $\beta$-hemolysis could be difficult to observe [7]. Therefore, negative samples should be further tested for other GBS strains using either a subculture on Granada agar plates, direct latex agglutination testing or (increasingly) molecular methods such as qPCR. Several clinical studies have been described for GBS detection by qPCR targeting the sip gene and have reported sensitivity between $95.4-97 \%$ and specificity between $84.6-$ 99\% (Supplementary Table 3); high sensitivity and specificity previously describes may be explained by the fact that the sip gene is conserved among all serotypes. On the other hand, none have declared analytical validation of the qPCR methodology, which could considerably improve future clinical validation studies. Although positive and negative controls are important when validating a result, a greater understanding of the methodology used, gained through analytical validation, is imperative. Our analytical validation parameters describe a trend that is similar to those seen with pathogens such as Trypanosoma cruzi (LOD, 0.23 and 0.70 parasite equivalents/ $\mathrm{mL}$ ) [13], Plasmodium knowlesi (analytical sensitivity, 10 copies/ $\mu \mathrm{L}$ ) [33] and the American H7 virus (10E3 and $10 \mathrm{E} 4$ gene copies per reaction) [34]. Finally, the availability of this standardised and validated qPCR method provides new possibilities for screening women in labor and helps to improve the detection of GBS strains using microbiological methods.

Using qPCR to detect the sip gene has been reported elsewhere, and sensitivity and specificity were acceptable $[16,19,20,35,36]$ (Supplementary Table 3). However, we established the limitations of this amplification process using analytical validation. Furthermore, our methodology, when compared with traditional methods currently considered to be the gold standard for GBS detection, shows $100 \%$ correlation. Nevertheless, the potential of this test should be explored because it could reduce swab incubation time or possibly allow direct extraction of genetic material. The technique developed here allows GBS to be detected in polymicrobial samples, and its specificity is superior compared to the microbiological method, which requires 3 to 5 days for incubation.

\section{Conclusion}

This kit accurately detects the bacterial agent GBS, it avoids cross-reactions with related bacteria and it provides $100 \%$ analytical specificity. It has a low LOD $(0.7$ $\mathrm{GE} / \mu \mathrm{L}$ or 14 genomes per reaction) and optimal performance, and it meets analytical needs, as shown in its linearity and efficiency data, which correlates with current screening methods. These preliminary results are favorable and provide the basis for a study with a greater sample size, which could confirm the effectiveness of this test using clinical validation.

\section{Supplementary information}

Supplementary information accompanies this paper at https://doi.org/10. 1186/s12884-020-03038-z.

Additional file 1: Table S1. The analysis of variance summary for data collected from three concentrations used to estimate the precision parameter. Note. DF: degrees of freedom; MS: mean of the squares; SS: sum of the squares.

Additional file 2: Table S2. Summary of the data from three concentrations used for estimating confidence intervals for repeatability and inter-laboratory precision. Abbreviation: Cl: 95\% Confidence interval. Repeatability results: at $2 \mathrm{GE} / \mu \mathrm{L}, 9.5 \% \mathrm{CV}[\mathrm{Cl}, 7.8-12.2]$; at $4 \mathrm{GE} / \mu \mathrm{L}, 5.9 \%$ $\mathrm{CV}[\mathrm{Cl}, 4.9-7.6]$; and at $100 \mathrm{GE} / \mu \mathrm{L}, 1.8 \% \mathrm{CV}[\mathrm{Cl}, 1.5-2.4]$. Intra-laboratory precision results: at $2 \mathrm{GE} / \mu \mathrm{L}, 12 \% \mathrm{CV}[\mathrm{Cl}, 9.9-14.1]$; at $4 \mathrm{GE} / \mu \mathrm{L}, 8.8 \% \mathrm{CV}$ $[\mathrm{Cl}, 6.6-9.3]$; and at $100 \mathrm{GE} / \mu \mathrm{L}, 2.3 \% \mathrm{CV}[\mathrm{Cl}, 1.9-2.7]$.

Additional file 3: Table S3. Results of various studies of qPCR analysis using the sip gene as the target for GBS detection.

Additional file 4: Figure S1. Alignment of the sip gene and oligonucleotides (118 bp).

Additional file 5: Figure S2. Detection of the Streptococcus agalactiae sip gene using qPCR. A Typical amplification plot using $2300 \mathrm{GE} / \mu \mathrm{L}$ as the DNA template. $d R n$, fluorescent signal using ROX as a passive reference. B The polymerase chain reaction (PCR) product from $\mathbf{A}$ was fractionated on a $2 \%$ agarose gel and visualised using gel red staining. Lane 1, DNA molecular weight marker, through analytical validation bp; lanes 2 and 3, PCR product, $2300 \mathrm{GE} / \mu \mathrm{L}$; lanes 4 and 5, no-template control.

Additional file 6: Figure S3. Daily runs used to estimate withinlaboratory precision. Three bacterial concentrations from ATCC 12403 (2, 4 and $100 \mathrm{GE} / \mu \mathrm{L}$ ), represented as $\log _{10} \mathrm{GE} / \mathrm{mL}$, were evaluated using a single-site design of 20×2×2 according to the CLSI EP05-A3 guidelines. A Values ( $\log _{10} \mathrm{GE} / \mathrm{mL}$ ) for the $2 \mathrm{GE} / \mathrm{mL}$ concentration obtained from four daily replications over twenty days. B Values $\left(\log _{10} \mathrm{GE} / \mathrm{mL}\right)$ for the $4 \mathrm{GE}$ / $\mathrm{mL}$ concentration obtained from four daily replications over twenty days. C Values $\left(\log _{10} \mathrm{GE} / \mathrm{mL}\right.$ ) for the $100 \mathrm{GE} / \mathrm{mL}$ concentration obtained from four daily replications over twenty days.

\section{Abbreviations}

ATCC: American Type Culture Collection; bp: base pair; CAMP: Christie, Atkins and Munch-Peterson; CDC: Centers for Disease Control and Prevention; CLSI: Clinical and Laboratory Standards Institute; Ct: Cycle threshold; DNA: Deoxyribonucleic acid; GBS: Group B Streptococcus; LOD: Limit of detection; LOB: Limit of blank; Mbp: Megabase pair; PCR: Polymerase chain reaction; qPCR: Real-time PCR; SIP: Surface immunogenic protein

\section{Acknowledgments}

The authors thank all members of the Bacteriology Laboratory of the Health Public Institute of Chile, in particular, Pamela Araya, Bianca Rojas, Soledad Castro, Ingrid Araya, María Soledad Prat, Joselin Hormazábal, Jennifer Díaz, Clara Orellana and Rocío Agüero.

Authors' contributions

SEI, DAS and AEV collected clinical samples; DFE, DD-D, CFH, DAS, RAM, CHP, DNB, CNO-B, PIA, RR and AEV performed analyses and interpreted the data; DFE, AMK and AEV conceived and designed the study; and DFE, DD-D and AEV made critical revisions to the manuscript. All authors have read and approve the final manuscript.

\section{Funding}

This study was supported by FONDEF D10i1202 (DAS, SEI and AEV) through the collection of clinical samples; by the Institute of Public Health in Santiago, Chile (DFE, DD-D, CFH, DAS, RAM, CHP, DNB, CNO-B and, RR AEV) through the performance of analyses and interpretation of data; and the Millennium Institute of Immunology and Immunotherapy, No. P09/016-F (DDD, (FH, DNB and AMK). 


\section{Availability of data and materials}

The datasets used during the current study are available from the corresponding author on reasonable request, but most of the data generated during this study are included in this published article and its supplementary information files.

\section{Ethics approval and consent to participate}

The procedures used in this study were approved by the Ethics Committee of Clínica Davila, Santiago, Chile. Written informed consent was obtained from all study participants and allowed the publication of this report.

\section{Consent for publication}

Not applicable.

\section{Competing interests}

The authors declare no competing interests.

\section{Author details}

'Sección de Biotecnología, Instituto de Salud Pública de Chile, Santiago, Chile. ${ }^{2}$ Millennium Institute on Immunology and Immunotherapy, Departamento de Genética Molecular y Microbiología, Facultad de Ciencias Biológicas, Pontificia Universidad Católica de Chile, Santiago, Chile. ${ }^{3}$ Departamento de Bioquímica y Biología Molecular, Facultad de Ciencias Químicas y Farmacéuticas, Universidad de Chile, Santos Dumont 964, Independencia, 8380494 Santiago, Chile. " Sección Bacteriología del Departamento Biomédico, Instituto de Salud Pública de Chile, Santiago, Chile. ${ }^{5}$ Escuela de Biotecnología y Escuela de Tecnología Médica, Facultad de Ciencias, Universidad Santo Tomas, Santiago, Chile. ${ }^{6}$ Centro de Genómica y Bioinformática, Universidad Mayor, Santiago, Chile. ${ }^{7}$ Department of Obstetrics and Gynecology, Faculty of Medicine, Universidad de los Andes, Santiago, Chile. ${ }^{8}$ Department of Obstetrics and Gynecology, Clínica Dávila, Santiago, Chile. ${ }^{9}$ Departamento de Genética Molecular y Microbiología, Facultad de Ciencias Biológicas, Departamento de Endocrinología, Facultad de Medicina, Pontificia Universidad Católica de Chile, Santiago, Chile. ${ }^{10}$ Facultad de Medicina y Ciencia, Universidad San Sebastián, Providencia, Santiago, Chile. ${ }^{11}$ Present address. Instituto de Salud Pública de Chile, Av. Marathon, Ñuñoa, 1000 Santiago, Chile.

\section{Received: 4 March 2020 Accepted: 27 May 2020}

\section{Published online: 09 June 2020}

\section{References}

1. Edmond KM, Kortsalioudaki C, Scott S, et al. Group B streptococcal disease in infants aged younger than 3 months: systematic review and metaanalysis. Lancet. 2012;379:547-56.

2. Verani JR, McGee L, Schrag SJ. Prevention of perinatal group B streptococcal disease-revised guidelines from CDC, 2010. MMWR Recomm Rep. 2010; 59(RR-10):1-36.

3. Madrid L, Seale AC, Kohli-Lynch M, et al. Infant group B streptococcal disease incidence and serotypes worldwide: systematic review and metaanalyses. Clin Infect Dis. 2017;65(S2):S160-72.

4. Russell NJ, Seale AC, O'Driscoll M, et al. Maternal colonization with group B Streptococcus and serotype distribution worldwide: systematic review and meta-analyses. Clin Infect Dis. 2017;65(S2):S100-11.

5. Lin FYC, Weisman LE, Azimi $P$, et al. Assessment of intrapartum antibiotic prophylaxis for the prevention of early-onset group B streptococcal disease. Pediatr Infect Dis J. 2011;30(9):759-63.

6. Patras KA, Nizet V. Group B streptococcal maternal colonization and neonatal disease: molecular mechanisms and preventative approaches. Front Pediatr. 2018;6:27.

7. Rosa-Fraile M, Spellerberg B. Reliable detection of group B Streptococcus in the clinical laboratory. J Clin Microbiol. 2017;55:2590-8.

8. Yancey MK, Schuchat A, Brown LK, et al. The accuracy of late antenatal screening cultures in predicting genital group B streptococcal colonization at delivery. Obstet Gynecol. 1996;88:811-5.

9. Davies HD, Miller MA, Faro S, et al. Multicenter study of a rapid 296 molecular-based assay for the diagnosis of group B Streptococcus colonization in pregnant women. Clin Infect Dis. 2004;39:1129-35.

10. Miller SA, Deak E, Humphries R. Comparison of the AmpliVue, BD max system, and illumigene molecular assays for detection of group B
Streptococcus in antenatal screening specimens. J Clin Microbiol. 2015;53: 1938-41.

11. Nishihara $Y$, Dangor $Z$, French $N$, et al. Challenges in reducing Grroup B Streptococcus disease in African settings. Arch Dis Child. 2017;102:72-7.

12. Six A, Firon A, Plainvert $C$, et al. Molecular characterization of nonhemolytic and nonpigmented group $B$ streptococci responsible for human invasive infections. J Clin Microbiol. 2016;54:75-82.

13. Ramírez JC, Cura Cl, da Cruz MO, et al. Analytical validation of quantitative real-time PCR 308 methods for quantification of Trypanosoma cruzi DNA in blood samples from Chagas disease patients. J Mol Diagn. 2015;17:605-15.

14. Brodeur BR, Boyer M, Charlebois I, et al. Identification of group B streptococcal sip protein, which elicits cross-protective immunity. Infect Immun. 2000;68:5610-8.

15. Rioux S, Martin D, Ackermann $H$, et al. Localization of surface immunogenic protein on group B streptococcus. Infect Immun. 2001;69:5162-5.

16. Bergseng $H$, Bevanger $L$, Rygg $M$, et al. Real-time $P C R$ targeting the sip gene for detection of group B Streptococcus colonization in pregnant women at delivery. J Med Microbiol. 2007:56:223-8.

17. McKenna JP, Cox C, Fairley DJ, et al. Loop-mediated isothermal amplification assay for rapid detection of Streptococcus agalactiae (group B Streptococcus) in vaginal swabs-a proof of concept study. J Med Microbiol. 2017;66:294-300.

18. Feuerschuette OM, Serratine AC, Bazzo ML, et al. Performance of RT-PCR in the detection of Streptococcus agalactiae in the anogenital tract of pregnant women. Arch Gynecol Obstet. 2012;286:1437-42.

19. Carrillo-Ávila JA, Gutiérrez-Fernández J, González-Espín Al, et al. Comparison of qPCR and culture methods for Group B Streptococcus colonization detection in pregnant women: evaluation of a new qPCR assay. BMC Infect Dis. 2018;18:305

20. Khatami A, Randis TM, Chamby A, et al. Improving the sensitivity of realtime PCR detection of Group B Streptococcus using consensus sequencederived oligonucleotides. Open Forum Infect Dis. 2018;5:ofy164.

21. National Committee for Clinical Laboratory Standards (NCCLS). Protocols for Determination of Limits of Detection and Limits of Quantitation; approved guideline. Wayne: NCCLS EP17-A, 2004.

22. Clinical and Laboratory Standards Institute (CLSI). Evaluation of Precision of Quantitative Measurement Procedures; approved guideline-third edition. Wayne: CLSI EP05-A3, 2014.

23. Clinical and Laboratory Standards Institute (CLSI). Verification and validation of multiplex nucleic acid assays; approved guideline. Wayne: CLSI MM17-A, 2008.

24. Bustin SA, Benes V, Garson JA, et al. The MIQE guidelines: minimum information for publication of quantitative real-time PCR experiments. Clin Chem. 2009;55:611-22

25. Morozumi M, Chiba N, Igarashi Y, et al. Direct identification of Streptococcus agalactiae and capsular type by real-time PCR in vaginal swabs from pregnant women. J Infect Chemother. 2015;21:34-8.

26. Raymaekers $M$, Smets $R$, Maes B, et al. Checklist for optimization and validation of real-time PCR assays. J Clin Lab Anal. 2009;23:145-51.

27. León CM, Muñoz M, Hernández C, et al. Analytical performance of four polymerase chain reaction (PCR) and real time PCR (qPCR) assays for the detection of six Leishmania species DNA in Colombia. Front Microbiol. 2017; 4:1907.

28. Breeding KM, Ragipani B, Lee KUD, et al. Real-time PCR-based serotyping of Streptococcus agalactiae. Sci Rep. 2016;6:38523.

29. Le Doare K, Heath PT, Plumb J, et al. Uncertainties in screening and prevention of group B Streptococcus disease. Clin Infect Dis. 2019;69:720-5.

30. Abdelazim IA. Intrapartum polymerase chain reaction for detection of group B streptococcus colonisation. Aust N Z J Obstet Gynaecol. 2013; 53:236-42.

31. Di Renzo GC, Melin P, Berardi A, et al. Intrapartum GBS screening and antibiotic prophylaxis: a European consensus conference. J Matern Fetal Neonatal Med. 2015;28:766-82.

32. Kwatra G, Adrian PV, Shiri T, et al. Serotype-specific acquisition and loss of group B streptococcus recto-vaginal colonization in late pregnancy. PLoS One. 2014;9:e98778.

33. Divis PC, Shokoples SE, Singh B, et al. A TaqMan real-time PCR assay for the detection and quantitation of Plasmodium knowlesi. Malar J. 2010;9:344.

34. Spackman E, Ip HS, Suarez DL, et al. Analytical validation of a real-time reverse transcription polymerase chain reaction test for pan-American 
lineage H7 subtype avian influenza viruses. J Vet Diagn Investig. 2008;20: 612-6.

35. Bergh K, Stoelhaug A, Loeseth K, Bevanger L. Detection of group B streptococci (GBS) in vaginal swabs using real-time PCR with TaqMan probe hybridization. Indian J Med Res. 2004;119(Suppl):221-3.

36. El Aila NA, Tency I, Claeys G, et al. Comparison of culture with two different QPCR assays for detection of rectovaginal carriage of Streptococcus agalactiae (group B streptococci) in pregnant women. Res Microbiol. 2011; 162:499-505.

\section{Publisher's Note}

Springer Nature remains neutral with regard to jurisdictional claims in published maps and institutional affiliations.

Ready to submit your research? Choose BMC and benefit from:

- fast, convenient online submission

- thorough peer review by experienced researchers in your field

- rapid publication on acceptance

- support for research data, including large and complex data types

- gold Open Access which fosters wider collaboration and increased citations

- maximum visibility for your research: over $100 \mathrm{M}$ website views per year

At $\mathrm{BMC}$, research is always in progress.

Learn more biomedcentral.com/submissions 